\title{
LANDSCAPE PRINCIPLES FOR SPACE DESIGN IN HARSH ENVIRONMENT: REVIEWING THE CASE OF EGYPT'S NEW TOWNS
}

\author{
Ingy Mohamed El-Barmelgy \\ Department of Architecture, Faculty of Engineering \\ Cairo University
}

\begin{abstract}
The current situation in the Egyptian new town spaces is a critical and an accumulated dilemma as there is no respect for the principles of a harsh environment. The spaces, especially in the low-income public housing have turned to be "a no-man land" or neglected areas. The main problem facing the designers of public spaces rehabilitation within lowincome public housing projects, is that these spaces are mostly unlivable environments and their design are not appropriate neither to the local environment of the town nor to the behavior of their dwellers. This leads us to the main aim of this paper, which targets urban designers, developers, and consultants to promote harmony, safety, activeness and compatibility in the development to the environment, through the set of design guidelines, principles for space generation levels, and standards regarding the landscape.
\end{abstract}

To achieve this aim, the paper consists of three parts. Part one, clarifies the theoretical basis for space generation at the three levels of design, finalizing each level by the main principles required for space generation with respect to a harsh environment. Part two, reviews lowincome public housing project spaces in four new towns in Egypt, highlighting the problems related to form generation especially the irrelevant landscape. The third part concludes the paper's findings related to 'space generation process guidelines' for a contextual level, space morphology level, and sensation and effects for users. Recommendations to achieve the desired spaces in terms of users' image, perception, senses to their spaces have been suggested.

\section{Key Words}

Harsh environment; Spaces in public low income housing projects; Space generation; Landscape; Space design guidelines \& principles.

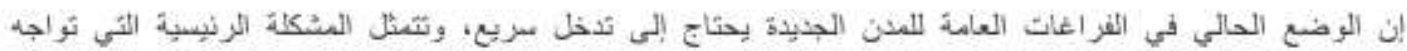

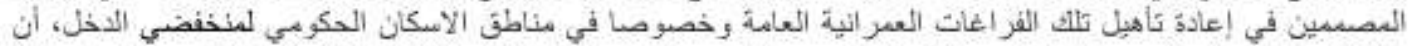

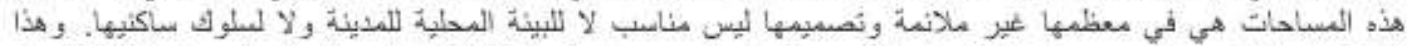

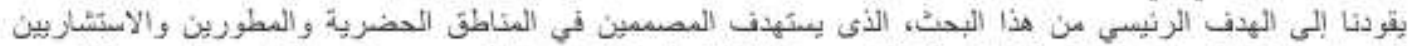

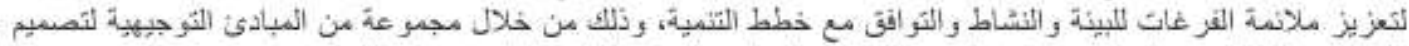

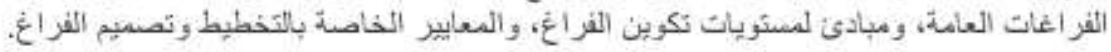

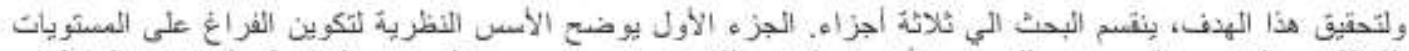

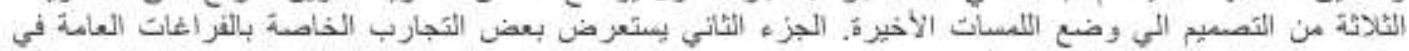

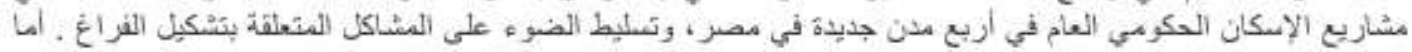

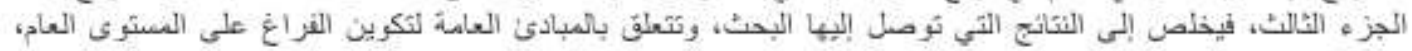

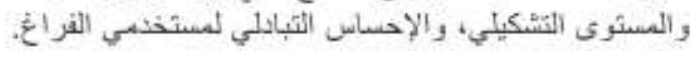




\section{Introduction}

In Egypt, there have been many attempts to solve the housing problems for the lowincome group by adopting a series of programs in the new towns. The in-between space planned in such projects, which we can call them the 'public low-income housing projects spaces,' is the main issue of this study. Traditionally, urban form in a hot harsh environment proved to be sustained and characterized by optimal protection against solar radiation by shading, which leads to compact settlements, narrow streets and small squares. The intent was always to create design excellence based upon a common set of design principles, which include consideration of the climate, context and design that are sensitive to human scale and the natural setting of a harsh environment.

It is a hard task to reach such design excellence in the Egyptian new town spaces as most designs are completely disregarding the environment. We need to regain our space senses, comfort, function and social organization. The paper is based on a practical project for spaces rehabilitation in one of Egypt's new towns in a harsh environment. This project helped in specifying and highlighting the main problems facing the designers in the rehabilitation of spaces in the public low-income housing projects. Spaces in such projects are mostly unlivable environments because their design is neither legible to the natural environment of the cities nor to the behavior of their dwellers. The term "open space" has turned to be perceived as a green space in the output of most of the designers, which led to the main problem in the spaces produced in Egypt's new towns. To achieve the desired spaces we cannot deal with landscape only, as landscape is considered the final stage we have to pay more attention to the design process itself.

The role of the designer is to fulfill the user's needs with respect to environmental, economical and functional relationships through the physical environment produced. To achieve this we have to be aware of the principles that guide the design in each level of the space generation in order to manage the product change. This directs us to the main aim of this paper, which is 'to derive design guidelines, principles and design criteria for space generation in public low-income housing projects located in new towns.' The paper's three part structure fulfills this aim. Part one, forms the theoretical basis, which highlights the form generation process in its three levels. Each level is further discussed with respect to users, ecology and economy, relating them to sustainability to conclude the main principles for space formation. Part two, introduces a case study applying the finalized principles' checklists at the three levels to the selected four new towns, focusing on the main problems at each level. Part three, states the findings and suggested recommendations for dealing with space design in a harsh environment. The paper concludes with special standardization for local materials and vegetation for spaces in public low-income housing projects.

\section{Research Highlights}

The paper provides guidelines, principles and design criteria for space design in harsh environment. The case study highlights the problems in the public low-income housing 
projects spaces in the Egyptian new towns through the different levels of design; planning, urban form generation and landscape. The paper's findings provide an opportunity for the urban designer to deal with public low-income housing projects through a multi-disciplinary design approach regarding users and economy in harsh environment.

\section{RELATING SPACES TO PLANNING FRAMEWORK}

Obviously, cities are more than just buildings. Yet, a powerful and highly durable component of our image of urban areas is constituted by the built environment itself (Andrew Maclaran, 2003). This part of the paper tries to connect the urban open space with its general context in the whole process of space generation.

\subsection{Open spaces in respect to the planning process}

Planning is a built up process, where the planner deals with different factors and aspects to produce the general plan of the town. The planning process could be concluded in three main stages: stage one is the city within its region to form the general development perspective; stage two, where the vision of the city is set, followed by the strategy and the land budget. Finally, stage three is to achieve the planning objectives in the form of a two dimensional master plan, where spaces are located as areas.

Figure (1) First level in space generation at the planning level

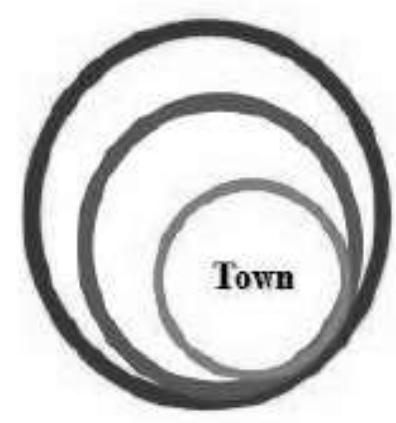

Town with respect to the Region

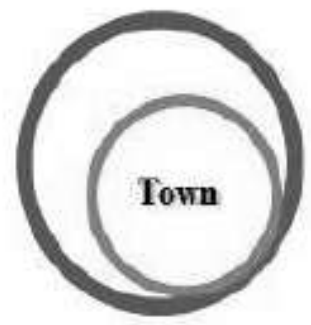

Vision with respect to location \& aspects

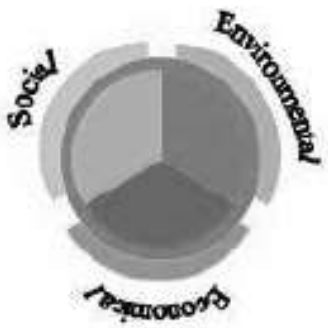

Developed plan \& services networks

\subsection{Relating open space to the development policy}

Development policy is targeted to serve the vision through achieving the main goals; a set of which are usually developed for planning purposes connected with main aims to derive main principles or design guidelines. The open spaces and their landscape are part of the planning main goals. Design guidelines seek to implement the adopted planning goals of the community with regards to public safety, health and welfare. The real task is to ensure that the following open space goals are included in the general framework of the development, (The Aga Khan Trust, 1996): 
- To ensure that the built environment is aesthetically pleasing and in harmony with the natural environment surroundings.

- To sustain the value of the town scenic natural features and resources.

- To promote and vary the town's quality of life.

- To minimize the change that might cause disturbance to the natural environment.

The above goals have to be integrated in the vision and the development policy to ensure that the natural environment I(climate and ground features) and the materials are compatible with respect to the users and the economy.

\subsection{Space network in respect to sustainability}

To reach the space in its desired form, the space in its context, passes through different stages of design. The first phase is the planning phase according to a development policy, which produces a design concept for the city as a whole. This stage is a two-dimensional stage finalized by a land use plan for services, residential, route network and space network. Moreover, this stage contains standardization for different uses with the proposed land budget.

To present this level of design in a sustainable form, the goals of sustainability should be integrated within the development plan. The main aspects affecting sustainability have to be clarified. These aspects concluded as, ecological, economical and social aspects, have to be considered in the design stage. Ecology is considered the main aspect in performing sustainability at the planning level. The urban designers ought to deal with microclimate to promote comfort (orientation, ventilation and vegetation), to deal with the landform to complement with nature and form the image for the user (topography, slopes and nature), and to deal with the economical aspects with respect to geology (uses in complement to location, land suitability analysis according to $\mathrm{Co} 2$ emission, water availability, micro climate... etc).

\subsection{Guidelines for space design in a harsh environment in the planning stage}

In view of the general goals of protection from the harsh climate and integrating the space with its context, the following guidelines have to be considered:

Respect for Topography Features

- To harmonize all structures with topography

- To benefit from microclimatic variation

Orientation to Achieve Comfort

- To optimize a comfort zone.

- Wind movement to achieve the required ventilation
Pattern \& Form Interrelation With Respect to Function

-To optimize reciprocal impact between spaces and buildings

\section{Exposure \&Imaging}

- For accessibility and safety reasons 


\section{URBAN FORM}

The second level is the urban form stage, which introduces the third dimension. The outcome of this stage is urban pattern, urban form, and the character regulation. The aim is to develop our plans from the two dimensional scale and model them in a three dimensional form. Urban form for spaces in a hot harsh environment should be characterized by optimal protection against solar radiation by shading, which leads to compact settlements, narrow streets and small spaces. An urban form may be defined as a special organization of land uses within physical context, the physical configuration providing the optimum fitness between the landuses, functions, activities, and linkage, and the site as most important feature (Alexander, C., 1977).

\subsection{Urban form and Site planning}

Site Planning for a hot harsh environment should consider topography, urban form, and external spaces $\&$ building design. Actually, when we revise any report for new towns the architectural design is always the focus. The issue is always the buildings and its orientation, shape \& volume, type $\&$ form and their immediate external spaces. This is to say, the site planning process for a specific location aims at the integration of site planning for each individual project with the overall context. Urban forms depend heavily on the climate and are designed differently in each climatic zone. The basic concerns are the provision of shading and air movement by alternative means. Urban forms cannot change the regional climate, but can moderate the city's microclimate and improve the conditions for the buildings and their inhabitants (SKAT, 1993).

Site planning generates the urban tissue integrating space design principles, scheming regulation, heights and volume, to produce the urban form (see fig.2). At this stage, space structure is half-way through as the closure, scale, and proportion of space is determined, providing the city's different types and levels. The city's different spaces should clearly identify the uses, hierarchy, access, space network \& connection, and their relation to the pedestrian network (Tibbalds,F.,1992).

Figure (2) Level two urban form generation

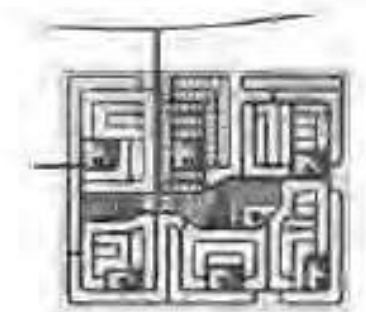

Plan + 2 Dimensional guidelimes= Form Sercices

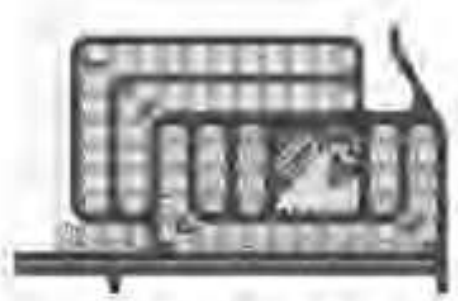

Form + Priaciples - Spaces Paditerns

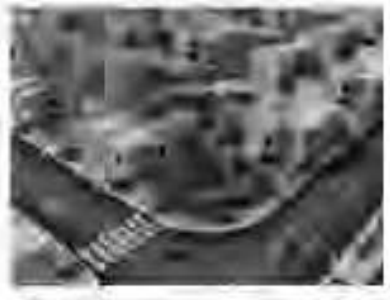

Types of Spaces \& Patteres 


\subsection{Urban form varies spaces (definition, types, and levels)}

"In our imagination of cities, it is these open spaces, rather than the buildings that surround them, that we remember. They are the places where people congregate to walk, shop, and picnic, to play and drive. It is these places that we use and in which we encounter each other: where we meet and enjoy and participate in that communal life we call city" (Halprin, L., 1972). There are different levels of spaces: a) public and social (extroverted \& interrelated for public use); b) private and introvert (for the individuals who seeks privacy). Moreover, types of spaces vary from streets, major plazas, minor plazas, water fronts, parks, squares, residential spaces, commercial spaces and small gardens. The study mainly focuses on a certain type of residential spaces, which are the public spaces in low-income housing projects. This type of space could be considered under housing spaces. To deal with this type of space, the designers should impose identity to give the desired sense of belonging, comfort, variety, accessibility, amenity, all in terms of cost and maintenance. These spaces are serving the activities of the dwellers in the first place as well as harmonizing the city's urban form. This type of space should be a part of the towns' different and integrated space networks in terms of hierarchy, uses and form (see Figure 3).

Figure (3) Different types of spaces

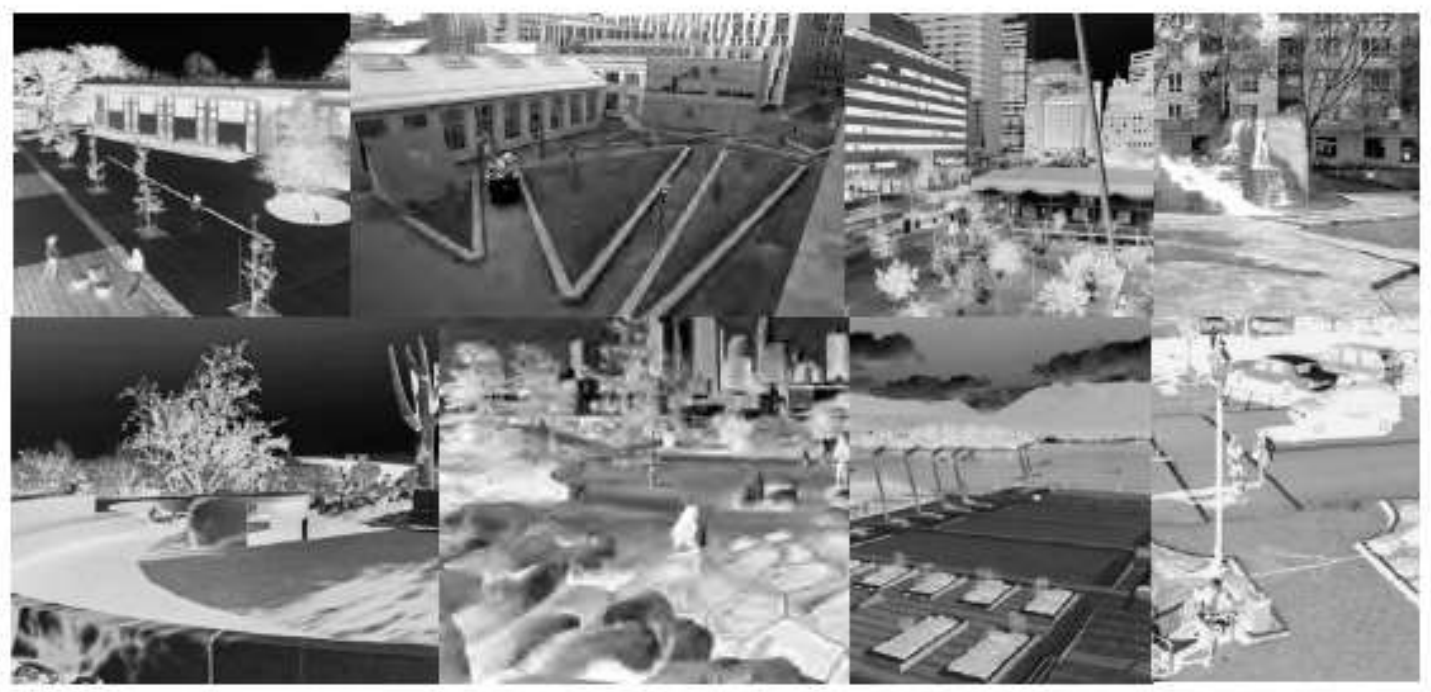

Source: www.pps.org.

\subsection{Urban form in terms of sustainability}

Regarding sustainability in urban form, many aspects should tackle ecology, social life, transport, landscape, buildings, and all other aspects of vibrant city living. The important issue is to make cities more suitable for people, paying more attention to the citizens, creating streets for pedestrians, cyclists, and public transport as a key for sustainable development away from previous policies regarding cars. 
Throughout numerous reviews of design manuals, to reach the sustainable urban form certain aspects are to be considered. Ecology, as the most important aspect, entails that each form feature should:

a) relate to the overall context by incorporating natural environment and features and by promoting pedestrian usability;

b) use and accentuate "land form" grading that reflects and fuses with natural grades, contours and existing site environment;

c) accentuate the vistas of the surrounding natural environment to identify significant visual resources;

d) minimize impacts of cut and fill slopes by the design of driveways and roads that complement the natural contours; and

e) integrate building design with the designs of street, space, hardscape and landscape elements, so that the building and grounds present a natural, integrated appearance (Girardet, H., 2004).

The social sustainability aspect should provide comfort to the users in such a harsh environment in spaces network with its relation to pedestrians and routes, amenity, variety, closure, scale, and proportion. The senses of the users are related to the town's micro climate and personal perception \& safety. Economic sustainability based on offering variety, appropriateness of uses and materials in spaces should be offered in the space formation.

\subsection{Urban form General Design Principles}

Urban form depends strongly on the climate and is designed differently in each climate zone. The urban form cannot change the regional climate, but it can moderate the city's microclimate and improve the conditions for the buildings and its external spaces and their inhabitants. Urban form design is affected by many factors through which we can conclude the following general principles to fulfil the user's needs and harmonize with the natural and economical factors (Deasy, C., \& Lasswell, T., 1985):

Environmental \& Climatic AmenityProvide a feeling of security to users.

- Where appropriate, offer relief from urban stress and enhance the health and emotional wellbeing of its users with regards to closure in clustering.

- Offer an environment that is physiologically comfortable at peak use times, with regards to sun and shade, wind, and the like in terms of scale and proportion.

- Encourage use by different subgroups of the likely user population without any onegroup activities disrupting the other's enjoyment.

\section{Function}

- Function of the space has to be defined, which have a primary influence on its type, form, size and layout.

- The needs of the users and their expectations with respect to comfort are very important determinants. 
Usability \& Adaptability

- Furnished to support the most likely and desirable activities.

- To be geared to the need of the user group most likely to use the space.

- Incorporate components that the users can manipulate or change.

- Easily and economically maintained, within the limits of what is normally expected in a particular type of space.(It is a place where communities come together to express and perform a variety of cultural activities - a space with open boundaries.) (Malone, K., 2002)

\section{Accessibility}

- To be easily accessed and seen by potential users.

- To be accessible to children and disabled people.

- Accessibility influences urban development and functional specialization of a place (Semm, K., \& Palang, H.,2010)

ImageabilityTo look beautiful and appealing on both the outside and inside.

- To be designed with equal attention paid to place

- as an expression of visual art and to place as a social setting.

- Generate space geometry for perception matters.

\section{Meaning}

- Clearly convey the message that the place is available for use and planned to be used (Lynch, K., 1964)

\section{OPEN SPACE FORMATION AND INTERRELATIONS}

The final level is the specific design of certain sites for fixed uses with the detailed plan for space and buildings. Mistakenly, many people perceive the term 'open space' as green areas in our developing countries. Open spaces are part of the urban tissue, affected by all elements of urban form. Therefore, space is the main shaper of urban form. Urban spaces as a part of urban form vary in type, level, form and scale. Further clarification for space, space formation, sensation and interrelation will be made.

\subsection{Space generation (space setting, structure and landscape)}

The primary quality of a successful open space is a "sense of place." An open space must have some kind of spacious order or definition before it can be acknowledged as a "place." Space designs should consider the following aims for the space itself with respect to its context (this should be set at the first level) Zetter, R., (2002): defined entry points to spaces, residential, and service areas; the encouragement of connections with the space network for the neighborhoods; diversity in the design of homes and neighborhoods, which is encouraged for residential subdivisions and planned communities (SKAT, 1993).

The second level in space generation is related to space structure \& setting where space design should consider the amenity, scale and proportion of space regarding climate and use, space closure and ventilation, and traffic control program. Diversity 
is very important in space structure for providing safety, interest and variety while maintaining a harmonious context.

Approaching the phase of landscape in the space generation, which is the third level, a design theme should be considered, identified by local materials, appropriate colors and roof types for local environment. The elevations should also vary in finishing materials or colors. At least two color schemes should be provided for buildings and roofs, varying the street appearance by providing different roof lines and shapes. Way-finding with directional signage, theme areas, and visual coherence should be provided.

Street character should be diverse in residential areas through the use of street trees or landscape themes, setbacks or architectural treatment. Site lighting (size, height and location) should be appropriate for use and site conditions. Softscape providing desired shade in the spaces, shrubs and zero type plants are appropriate.

Various colors and textures of landscape are required to achieve identity in related identical clustering spaces. The primary purpose of the landscape is that the design should encourage a sense of place and that landscaping should be in harmony with the site. In doing so, scenic qualities should be preserved, local and regional character should be revealed, and the efficient use of the site should be improved.

All these aims should be translated to design criteria in terms of space structure. The structure of the space is directly related to the environment and to the sense and the attitude of the user. This structure of the space gives the user space scale, proportion, geometry and closure.

\subsection{Landscape, space components and interrelations}

Landscape can be defined as hardscape and softscape. Hardscape is resembled in space furniture, space walls, space floor, lighting, seats, signs, and water in space, steps, bollards, barriers, walls, bus shelter and telephones. Softscape could be easily identified as all the vegetation elements in space, flooring, barriers, walls, shading trees, focal trees, palms, ornaments and shrubs.

The idea to be clarified here is that a space without landscape to the user is like a home without furniture; though this home might be in a very rich environment overlooking a nice view, but not usable without its finishing and furniture for its inhabitants. Space is no exception, even if we reach by now (in the form generation for space) the ideal location, the perfect size and structure a great part of the senses and uses of these spaces need to be drawn by the space components and landscape (see Figure 4).

The softscape is what creates the senses in space, while the hardscape is what makes people interact and use the spaces. Without landscape, spaces are neglected and of no use. The landscape either serves the space or blocks it. 
Figure (4) Street furniture (soft \& hardscape)

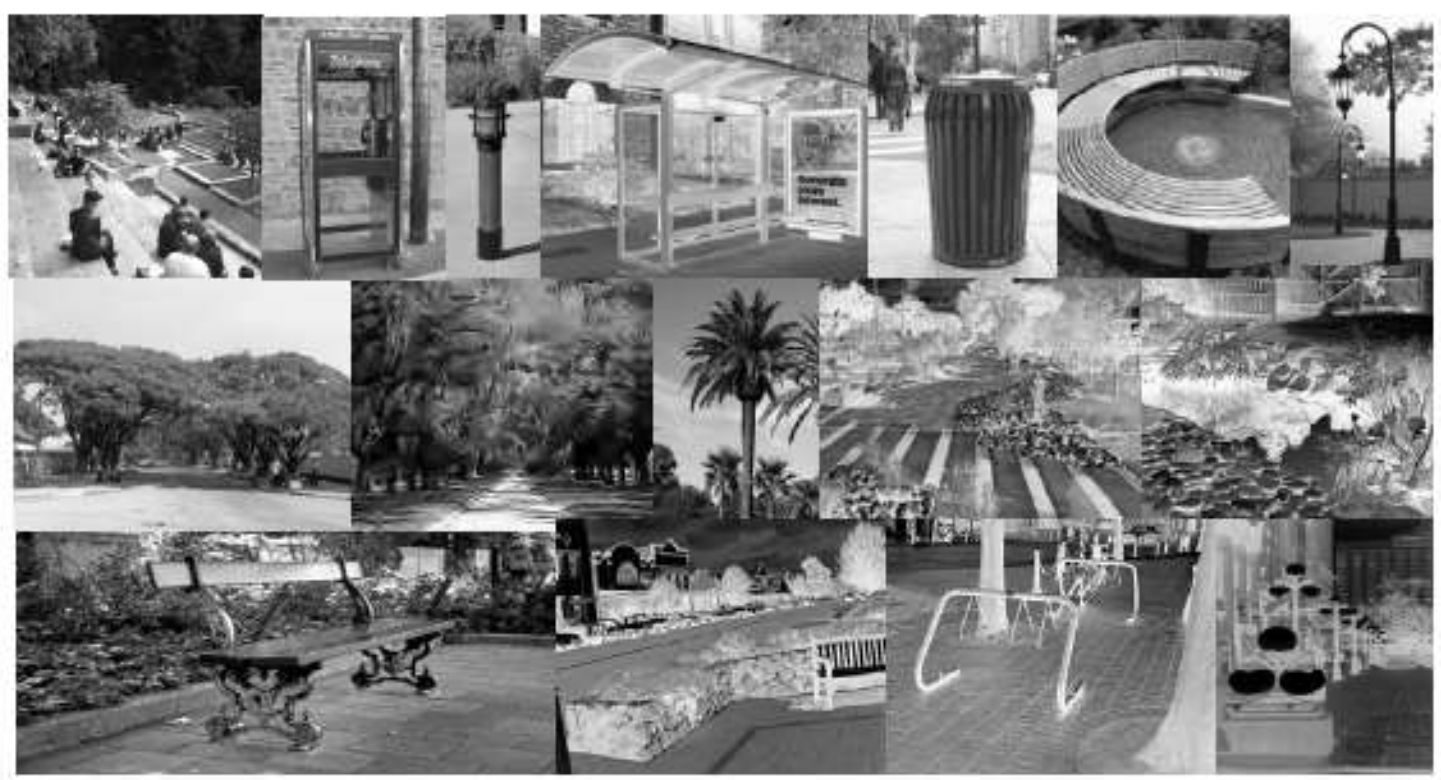

Source: www.pps.org.

\subsection{Detailed space plan and landscaping in respect to sustainability}

Open spaces should be designed to be meaningful and useable, provide pedestrian trails within new communities, and connect with the towns' overall trails and parks. The plan should distribute a usable open space to encourage pedestrian access. The location and design of open space should take advantage of views, existing vegetation and land compatibility. The intention should be:

a) to provide an effective form of communication while preserving the scenic beauty of the desert environment

b) ensure that the signage is clear, compatible with the character of the architecture and adjacent neighborhoods

c) provide the essential identity of and direction to facilities in the community. In the perspective of making places more sustainable, one needs to address the issue of different scales.

Some fundamental principles need to be put in place at a strategic planning level so that detailed solutions can be effective. "There needs to be enough space for nature and landscape elements to grow in the first place before we can select the most appropriate and beneficial plants for the desired effect " (Ritchie, A. \&Thomas, R., 2009).

Sustainability cannot be achieved by any means at that level in design of the detailed plan if not considered before in the planning process and the urban form (for space location, space setting in the nature, space structure finalized by the landscape plan). 
The landscape plan should be oriented toward sustainability; we need to create senses (comfort, relaxation, amenity, identity, and variety, all conveyed by the landscape, hardscape offering seats, lighting, pavements, bus shelters, and shades) through landscape to the user with respect to maintenance and economical matters. Softscape should accentuate and reveal the senses, create shade for comfort, highlight pedestrian ways, provide enclosure for amenity and relaxation, ornaments and landmarks for identity.

\subsection{Design criteria for space landscape in harsh environment}

Designs using vegetation in the urban environment are of functional, aesthetic as well as climatic importance for its radiation absorbent surface and its evaporative and shade-giving properties. The vegetation in and around cities also has definite effects on air movement. Vegetation is desirable both for providing shade, thus reducing the temperature in such shaded areas, and for reducing the effects of strong solar radiation on the walls of buildings and structures (SKAT, 1993).

In a hot harsh environment with limited water resources, plants with high water requirements may not be possible, but plants adapted to local conditions are always advantageous. When selecting the plant material, it is strongly advisable to consult local plant nurseries about their stocks and their experiences. The suitability and performance of plants depend highly on the specific local conditions. Developed design criteria for landscaping should be provided:

\section{Accentuate comfort \& safety}

- Create the space atmosphere providing shade, ventilation, security,...)

- Visual access for public safety should be provided.

- Caution with factors which impair the safety of the space, traffic, storms, and control.

- Create a sense of enclosure in seating and gathering areas.

- Space lighting (size, height and location) should be appropriate for the use and site conditions.

\section{Meaning \& human aspects}

- Creating desired senses (sense of belonging, privacy, variety, identity).

- Enhance visual character and provide amenities for pedestrians.

- Use landscaping to help define pedestrian circulation and building entrances.

- Provide landscaping to highlight the built environment.

- Intensify visual qualities by using a variety of plants with different colors, forms, smells and textures.

\section{Preserve nature}

- The adequate application of the available local resources and materials are taken into consideration.

- Provide plantings to accentuate and enhance an aesthetic appeal as well as to add local character to the site.

- Plant trees to provide shade for pedestrians, and automobiles.

- Vegetation plan consider water resources. 


\section{Consider space sustainability \& maintenance}

- One of the main problems of public spaces in the long run is proper maintenance.

- This aspect must be considered in the choice of materials and construction details in the landscape plan that serve the local harsh environment.

\section{Cost regarding economical statues}

- Economic aspects also influence the materials choice but designers should count lifetime.

- Management for space and the surrounding built environment, material durability, and appropriateness.

\section{CASE STUDY}

The case study of this paper is concerned with the Egyptian's new towns. The problem of the residential public spaces, as most of these new towns' development plans, is that there's more concentration on the housing units themselves, sizes, types, density, and building regulations, with less attention paid to the general layout of spaces that deals with left-over spaces as greens. Though vegetation is desirable both for providing shade and reducing the temperature in such shaded area, yet, in hot harsh environment areas with limited water resources, plants which adapt to local conditions are always advantageous. Moreover, plants increase the value of indoor and outdoor living spaces. Yet, our new towns are far away from this desirable landscape vegetation plan that we seek. However, the study reviews four new towns concluded as 6th of October, 10th of Ramadan, 15th of May and Sheik Zayed.

\subsection{Review Egypt's new towns site plans in relation with the public housing spaces in low income projects}

The four new towns are located near the outskirts of Greater Cairo Region. What is common among them is the hot harsh environment of the desert where they are located. The urban form of the towns is completely in disharmony with the environment there. This is because there is no sign for a sustainable development plan for the location in concern with the open space network regarding the principles concluded (see 1.4 Guidelines stage):

\section{Respect for topography features:}

The towns respect the landform features in term of uses with less concern to the desert environment, topography and climate.

\section{Achieve comfort:}

Attention is paid to ventilation and orientation of spaces network and route network at this stage.

\section{Pattern and form interrelation:}

With respect to function, there is neither clear patterning in space integration of spaces to pedestrians, nor a hierarchy of the spaces themselves. 


\section{Exposure and imaging:}

At the scale of site planning, no imaging is created in the four cases as there are monotony and repetition of spaces with the same setting with no focus on linkage and accessibility (see 4.1 Table 1 ).

\subsection{Reviewing space structure for public housing spaces in low income projects}

Reviewing the structure of low income housing governmental spaces in the four towns seems to be the same. There is complete ignorance of the scale, proportion of space regarding environmental matters, as well as the geometry of space regarding its appropriateness to the use and human element (see 4.2 Table 1 )

\section{Environmental and climatic amenity:}

In the four cases there is rarely accounting for climatic amenity in terms of space, scale and proportion, neither is there an identity in clustering nor security according to reputation.

\section{Usability and adaptability:}

There is no furniture to support the activities. The space design does not consider the maintenance matter. Functions of the spaces are not served with a primary influence on its type, form, size and layout. The needs of the users and their expectations with respect to comfort are fulfilled.

\section{Accessibility:}

The spaces are easily accessible and can be seen by car, while pedestrian linkages are not defined.

\section{Imageability and meaning:}

The spaces in the four towns clearly convey the message to the users that they are of no use and are neglected.

\subsection{Review for space landscape and vegetation of public housing spaces in low income projects}

The vegetation in spaces of low income housing governmental sites is too far from any sustainable principles, criteria or standard. No senses can be conveyed from them except negligence and poorness.

Disharmony between the vegetation elements and nature of harsh environment, results from the use of grass, a very high consumer of water, in every single space with no regards to maintenance and efficiency. The trees are scattered with no order or even consideration of space activities (see 4.3 Table 1).

Conclusions regarding the criteria for space landscape with respect to the four towns (see 3.4 'design criteria') are as follows: 
Table (1) Case Study analysis for space formation

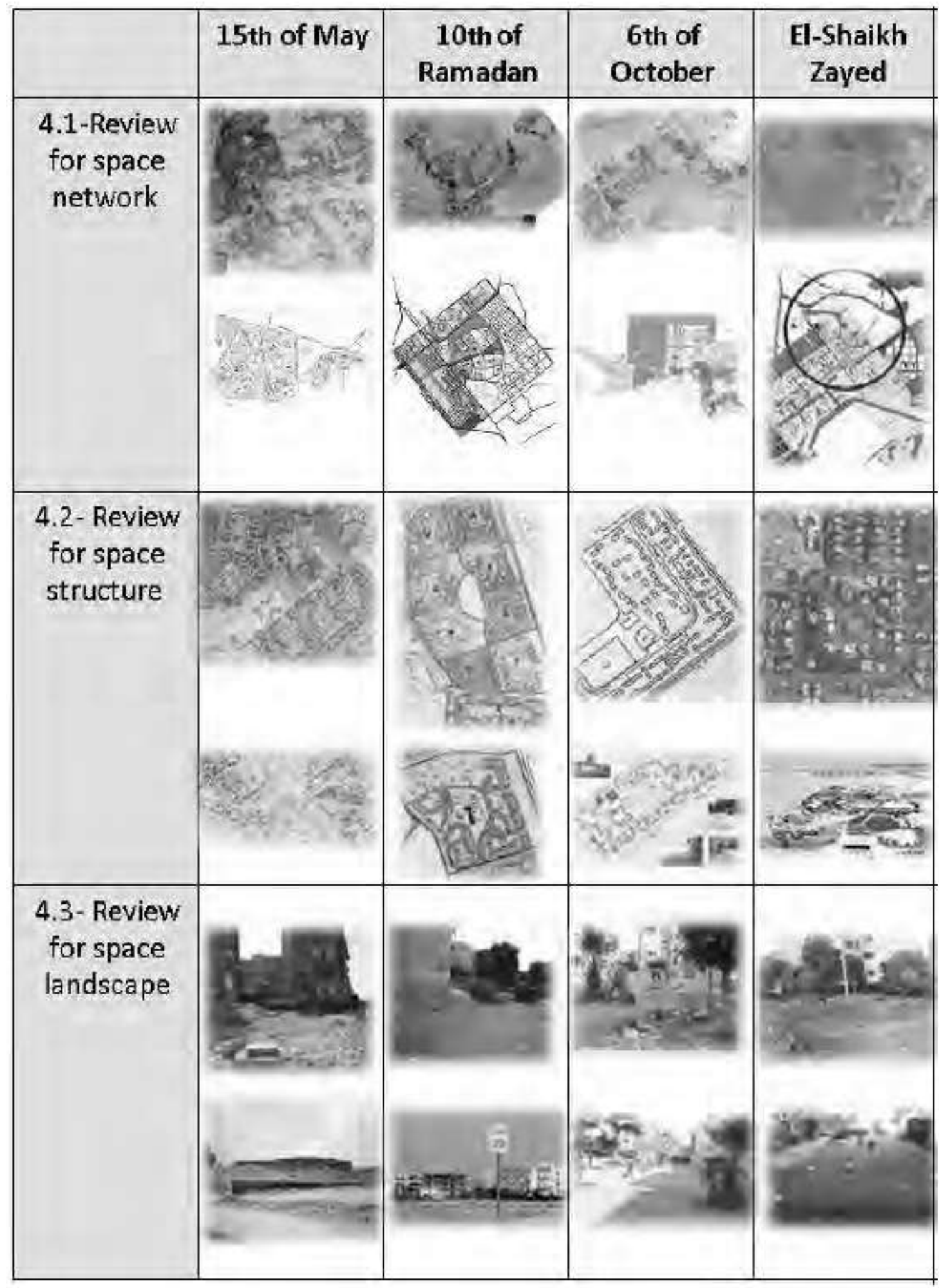


Accentuate comfort and safety:

A glimpse of shade is created in the four cases regardless of the activities. The visual access is not provided in a good quality; a sense of enclosure is created in some spaces by the clustering; the space light is either unavailable or inappropriate in terms of lighting size, height and location neither for the use nor for the site conditions.

\section{Meaning and human aspects:}

No senses of belonging, privacy, variety, identity, are created to enhance visual character and provide amenities for pedestrians. There's no clear use of landscape to define pedestrian circulation and building entrances. The visual qualities are also very poor with respect to plants (grass, shading trees, and a glimpse of shrubs).

\section{Preserve nature:}

The local resources and materials are not taken in consideration; the existing plant trees provide shade for space but not for pedestrians or automobiles; vegetation plan do not account for water recourses grass is highly used.

\section{Consider space sustainability and maintenance:}

This aspect is not considered in the choice of materials and construction details in the landscape plan that should serve local harsh environment. Costs regarding economic aspects should influence the materials' choice but designers should also count lifetime. There is no management for space and the surrounding built environment, material durability, and appropriateness.

\subsection{Case study findings}

The spaces in public low-income housing projects in the four new towns suffer from the same problems. The concluded problems of the three levels of space generation regarding, users, the environment and the economy are as shown on Table (2).

Table (2) Problems at levels of space generation

\begin{tabular}{llll}
\hline Space generation & Users & Environment & Economy \\
\hline Level 1 & $\begin{array}{l}\text { No image for clear } \\
\text { space pattern }\end{array}$ & $\begin{array}{l}\text { Some of the master } \\
\text { plans counts the } \\
\text { natural feature }\end{array}$ & $\begin{array}{l}\text { Variety for space } \\
\text { use and location at } \\
\text { the planning level } \\
\text { only }\end{array}$ \\
\hline Level 2 & $\begin{array}{l}\text { No clear perception } \\
\text { for the space }\end{array}$ & $\begin{array}{l}\text { Dis-amenities for } \\
\text { climatic conditions }\end{array}$ & Accessibility matters \\
\hline Level 3 & $\begin{array}{l}\text { No good senses } \\
\text { revealed through } \\
\text { the spaces }\end{array}$ & $\begin{array}{l}\text { Non comfortable } \\
\text { spaces }\end{array}$ & $\begin{array}{l}\text { Non appropriate } \\
\text { landscape material }\end{array}$ \\
\hline
\end{tabular}




\section{CONCLUSION}

In seeking sustainable places, the solutions may vary but the principles guiding those solutions to seek the desired plans are predictable. Accordingly, to reach the spaces in their desired form, more attention should be paid to the principles of design at each stage or phase of space generation.

The desired form of spaces is reached through understanding the contextual, environmental, social, and economical aspects etc. Space elements or components should be considered along with the space setting, context, hot harsh environment, and region. Landscaping must be considered as an integral element of the project during site planning, as it's not a kind of magic that is performed to make everything looks great at the end.

\section{FINDINGS}

To reach a legible space design we have to pass through its different stages in the sequence of building up the complete process of space generation. Certain features have to be identified at the planning stage; others at different stages as listed in the built-up process where the user should be always the focus of the design (Figure 5).

Fig (5) Built-up process from space to place

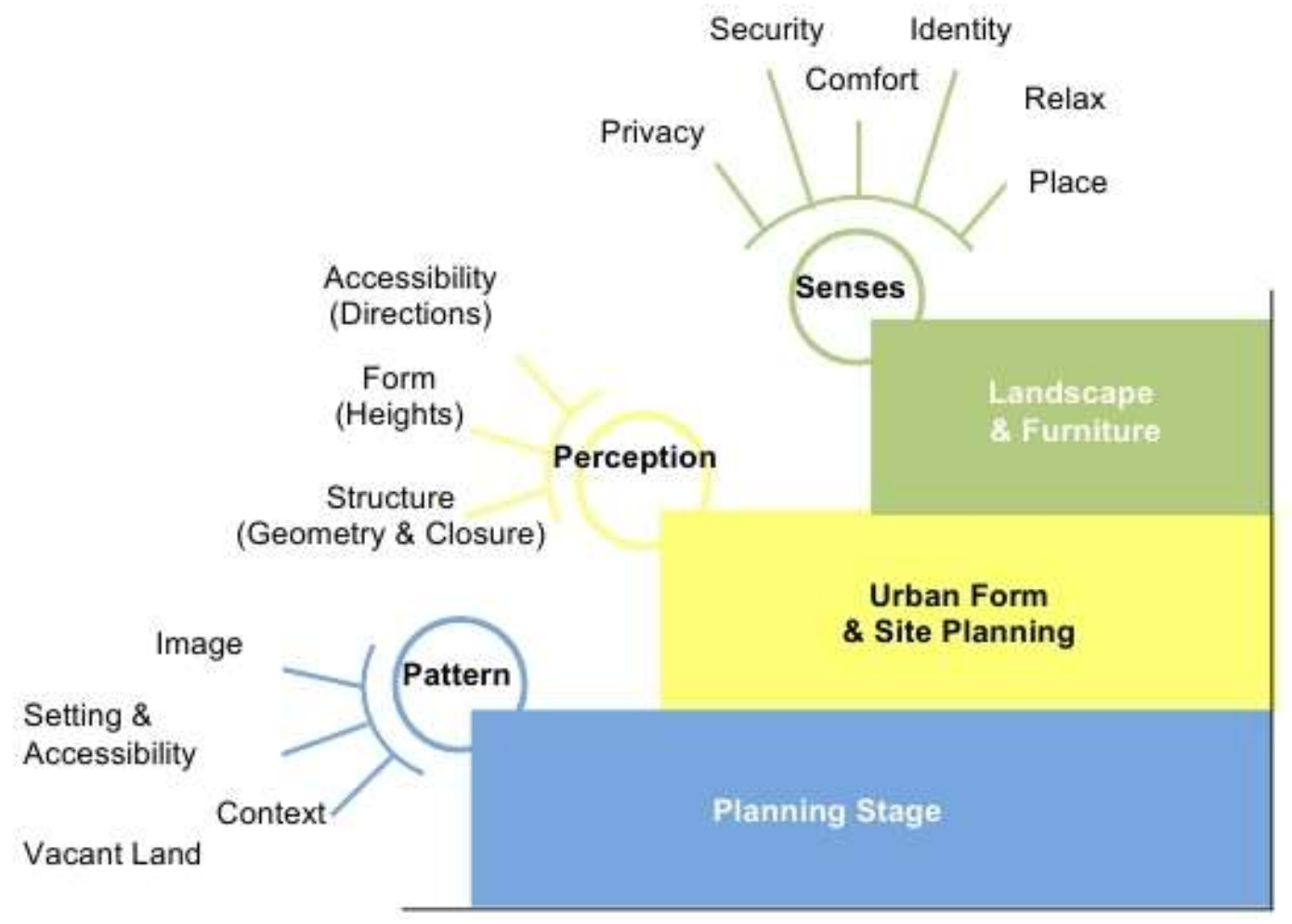


Main principles \& design criteria for space in public housing project are as follows:

\section{General Context Level affecting the image and patterns for user} (Site planning scale):

1. Space urban setting \& Inclusiveness

2. Respect for Context $\&$ Carefulness in dealing with nature

3. Functional relationships \& internal links and patterns

\section{Morphology of Space affecting the perception of the user} (Space formation scale):

1. Space in the 3rd Dimension

2. Structure of Space (scale, proportion, geometry and enclosure.)

3. Environmental setting

\section{Sensation and effect for user}

(Space components scale)

1. Comfort (shade, ventilation, security,...)

2. Sustainability (space components material)

3. Meaning (sense of belonging, privacy, variety, identity)

\section{RECOMMENDATIONS}

Space to regulate and organize the towns' urban pattern on the planning level:

- Provide open space pattern to create the town character placing main spaces at project entries, related to main buildings, to be visible from roadways within residential areas.

- Allowing green areas of plants around and within the town to provide shade and cool air based on the need, and the natural suitability with respect to climate and water resources.

- Creating urban form to moderate the microclimate, encourage clustering of structures as a means of preserving open spaces environmentally as well as visually (form, structure, scale and accentuating perception).

- Respect the accessibility maters, as to locate open space adjacent to collectors to serve as a "focal point" for community.

- Encourage pedestrian/bicycle circulation that connects neighborhoods with schools and commercial centers urban services and daily functions within walking distance; wide roads can thus be omitted or at least reduced.

- Design major spaces to be nodes for communities to address a wide variety of activities for all ages, active and passive, i.e. walking, sport, neighborhood events, etc. 
To maintain the space urban form and perception:

- Avoid large scale open spaces within the city where hot air can collect during the day and which are conducive to dust storms.

- Design buildings at the ground or pedestrian level that express human scale. This can be done by using the appropriate sizing of openings, level of detail, articulation and use of textures.

- Harmony with the natural environment is encouraged. Building should not dominate the land, but conform to the natural landscape.

- Express pedestrian scale features at the ground level, such as planters, benches and textures.

- Project design should consider and integrate all elements of landscape and accessibility.

- Design suitable building forms and clustering to perform closure.

Landscaping should be limited to native and desert plants. Design of landscaping should enhance local character, minimize water usage, and provide amenities for pedestrians:

- Control and moderate the effects of undesired winds by landscape.

- Provide maximum shade in summer.

- Adopt plants to resist desert environment xerophytes that require little or no water, use of local plant materials is encouraged

- Plant materials that require large watering amount such as grass and palms are discouraged.

- To minimize water consumption, plants having similar water use should be grouped together in district hydro zones.

- Caution is needed in selecting plants appropriate based to the climatic, geological and topographical conditions of the site.

- Nature features such as drainage swales should be integrated in the over all space planting designs.

\section{References}

Architecture Sustainable Landscape Design in Arid Climate (1996). The Aga Khan Trust for Culture.

Alexander, C. (1977). A pattern language, Oxford University Press.

Ashworth, G. J. \& Larkhalm (1994). Building a new heritage, Routledge, London.

Baron, B. (1977). Psychology: understanding behaviour, Hol-Saunnders International Editions.

Bechtel, R., Robert, W. \& Michelson (1987). Methods in environmental and behavioural research, Van Nostrand \& Reinhold company, New York.

Bruce, V. \& Green, P. (1985). Visual perception physiology, psychology, and ecology, Lawrence Erlbaum associates, London. 
Booth, N. (1983). Basic elements of landscape architectural design, Elsevier Science Publishing Company, New York.

Canter, D., \& Terence, Lee (1974) Psychology and the built environment, John Willey \& Sons, New York.

Chidster, M. (1986). The effect of the context on the urban plazas, New York: Rizzoli.

Coccossis, H., \& Nijkamp, P. (1995). Planning for our cultural heritage, Aldershot, Avelery.

Deasy, C., \& Lasswell, T. (1985). Designing places for people, New York.

Green, B., and Barrie, B. (1981). Space dimensions of the human landscape, Yale University Press, New Haven \& London.

Cooper Marcus, Clare and Carolyn Francis, eds. (1999). People places: Design guidelines for urban open space. New York: John Wiley \& Sons, Revised 2nd Edition.

Girardet,H. (2004). Cities people planet, Wiley\& Sons Ltd, UK.

Halprin, L. (1972). Cities, MIT Press, NY

Maclaran, A. (2003) Making space: Property development and urban planning, Hodder Arnold, Oxford University Press Inc, New York.

Ritchie, A. \& Thomas, R. (2009) Sustainable urban design: An environmental approach, Taylor \& Francis, London.

Semm, K.,\& Palang, H. (2010). Landscape accessibility: Spaces for accessibility or spaces for communication? Living Rev. Landscape Res., 4, http://www.livingreviews.org//rlr2010-4

Tibbalds, F. (1992). Making people-friendly towns, Longman Group UK.

Zetter, R. and R. R. White, eds. (2002). Planning in cities: Sustainability and growth in the developing world. London: ITDG Publishing.

Malone, K. (2002). Street life: youth, culture and competing uses of public space, Environment and Urbanization, http://eau.sagepub.com

http://www.denvegov.org/portals

http://www.Addendum A: Design Guidelines

http://www.pps.org

http://www.climate.com, Climate Responsive Building (skat,1993) three design rules

http://www. Climate responsive Building- Appropriate building construction in tropical and non-tropical regions (SKAT, 1993) 